\title{
In defence of Shockley
}

SIR-The obituary of William B. Shockley (Nature 341, 180; 1989) does not do justice to a remarkably creative scientist, focusing as it does on what might be called the aberrations of his later years and almost neglecting his truly creative period between the late 1930 s and the early 1950 s before he left the Bell Telephone Laboratories. Moreover, it does not say that his intense and (to my mind) ill-conceived concentration on socio-genetic matters occurred after a head-on automobile collision in which he was almost killed. His Palo Alto surgeon, Dr Bert Davis, told me at the time that he was on the operating table for some seven hours in a touch-and-go situation.

I first met Shockley in Palo Alto in 1930 when we were both undergraduates, he at Caltech and I at Stanford. We formed a semiprofessional friendship which lasted until we disagreed on assessments of the actual value of IQ tests.

We both ended up doing graduate work in the eastern United States. Moreover, we both worked in the field of solid-state physics during our most productive research years. He returned to California in 1954 to start his ill-fated semiconductor company which, through the accidents of fate, had a profound catalytic effect on the evolution of Silicon Valley.

Shockley's graduate work at Massachusetts Institute of Technology was carried out under the leadership of John Slater. He joined the Bell Telephone Laboratories in 1936 and there learned to seek novel concepts in the field of electronics - a grooming that paid rich dividends. Early in the Second World War, both he and James Fisk, later director of the laboratories, carried out a preliminary investigation of the design of self-sustaining nuclear reactors - an endeavour that was inevitably superseded by the work of others once the Manhattan Project was formed. He spent the remainder of the war working in operations research and became a key adviser to General $\mathrm{H}$. $\mathrm{H}$. Arnold, head of the Air Corps. His imaginative analysis of the effects of the conventional bombings of Japan proved remarkably accurate when on-site observations were made later.

From 1945 until he left the laboratories in 1954 were his years of greatest scientific creativity, where he displayed remarkable gifts for interrelating theory and phenomenology in bench-top observations gifts which to me at least were reminiscent of those of Enrico Fermi. During this period, Shockley carried out informative investigations in connection with magnetic domains, the factors involved in photolysis of the silver halides and the properties of dislocations. The climatic work, of course, was that carried out in cooperation with John Bardeen and Waiter Brattain, whose experience was essential to its success. Shockley's first solo attempt to develop the equivalent of what is now termed the field-effect transistor failed for reasons that Bardeen was in an ideal position to appreciate from his research and experience on surface states of solids.

One can perhaps find in his earlier outlook towards social matters the roots of the attitudes that led him into his justly unpopular and clearly unprofitable excursions into what he regarded as the exact science of racial genetics. Shockley always kept his own counsel and never sought social companionship for its own sake. I am inclined to believe, however, that the residual effects of his near-fatal accident cannot be ignored in evaluating his activity in later years.

Rockefeller University,

FREDERICK SEITZ

1230 York Avenue,

New York, New York 10021-6399, USA

\section{How courageous?}

SIR-One must applaud the fact that he shows some concern about the injustices of the apartheid system, but when your correspondent John Ormerod "sticks out his neck" (Nature 341, 99; 1989) this is a somewhat different affair than when South African academics (whom he does not wish to support) do so - vide the case of David Webster, murdered for his stand against racism. Further, Ormerod's chosen method of opposition ("saying No to science from South Africa") avoids entirely the issue of who if anybody should teach black South Africans at the tertiary level - does he believe tertiary education is a luxury they do not need? Or is it just that he thinks they do not need to know any science?

\section{SISSA, Strada Costiera 11,}

GEORGE ELLIS

Miramare, Trieste,

Italy 34014

SIR-I have just read the letter by Jan Ormerod of Oslo (Nature 341, 99; 1989) explaining how courageous he is to say "no" to science from South Africa. In the special environment in certain university circles in Norway, I think it would take more courage to say "yes". These people seem to base their opinions only on information from the 'victims' and activists living in what are called the frontline states. As proof of Norway's stand (or lack of it), I have the following story to tell.

This summer, the Agricultural University at Aas held a symposium with participants from all over the world. The subject was "Preharvest sprouting in cereals". A representative from South Africa was denied participation. When I asked why, I was told that Norwegian boycott laws disallow South African participation in scientific meetings. But, I was told, "this does not apply to medicine, in which field South Africa has so much to offer".

In other words, we boycott only if it does not hurt us. It has been much publicized that South Africa has its flaws, but people there are certainly working to change things for the better. Remember, Rome was not built in a day. South Africa has a lot to offer, not only in medicine but also in agriculture, which in the near future will have to cope with the problems of feeding the world's everincreasing population ( 85 million a year) on a steadily decreasing acreage. I hope Ormerod and the Norwegian policymakers will soon realize they must change their attitude towards South Africa - that would really help the 'victims' too. Closing doors seldom solves problems, it just creates them.

Søndre Ski Gård, 1400 Ski, Norway

\section{Hidden dangers}

SIR-It is easy to write, as does Bo Wahlström (Nature 341, 276; 1989), of banning carcinogenic, mutagenic and teratogenic chemicals. Few, however, realize how widespread these properties are (at least in animal experiments).

Consulting a standard work (Sax, Dangerous Properties of Industrial Materials), I discover that the following are suspect carcinogens and both mutagens and teratogens: ethanol, fructose, lactose and maltose. If I restrict myself to experimental teratogens and mutagens, sucrose, sodium chloride and retinol (vitamin A) are added to the list.

All these must, then, be placed well up Wahlström's multiproblem list for imminent banning.

Does Wahlström propose to ban them? If so, how? If not, why not, by his criteria? If he will restrict his choice to problems revealed by human epidemiological studies, he will still have to ban retinol, and its precursor carotenes - which prove ever so slightly fatal for Swedes.

The probability is that, given suitable experimental techniques and appropriate test species, one can show that any and all substances are carcinogenic, mutagenic and teratogenic. Unless, of course, they are more immediately deadly by other means. Perhaps it would be more appropriate to ban chemicals that show none of the above properties, and leave ourselves something to eat.

\section{Upper Rosemary Hill,} Kenilworth, UK
SIMON ROMAN

NATURE VOL $342 \cdot 30$ NOVEMBER 1989 